\title{
Assessment of carotid intima-media thickness and carotid plaque formation among patients with ischemic stroke and hepatitis $C$ virus infection
}

\author{
Ahmed Osama ${ }^{1}$, Yossri Ashour ${ }^{1}$, Reda Abd El-Razek ${ }^{1,2^{*}}$ and Dina Monir ${ }^{1}$
}

\begin{abstract}
Background: Cerebrovascular diseases are well known all over the world to be among the top list of the causes of death. One third of ischemic stroke could be regarded to plaque rupture and embolization. The actual mechanisms have not been exactly understood, but inflammation plays a pathogenic role. Patients with hepatitis C virus (HCV) proved to have a high level of inflammation. Replication of HCV within the brain endothelial cells and carotid plaques and, recently, the consideration of HCV as playing a role in risking for atherosclerosis rose the question of the role of HCV in cerebrovascular diseases.

Objective: Evaluating the role of infection with HCV among patients with stroke through assessment of carotid atherosclerosis.

Patients and methods: A cross-sectional study was carried out on 100 patients with ischemic stroke, aged 40-60 years, enrolled from the Neuropsychiatry Department of Suez Canal University Hospital. Patients were classified into 50 HCV-positive patients and 50 HCV-negative patients. All patients were assessed for HCV and the traditional risk of stroke as they were subjected to complete neurological examination, assessment of vascular risk factors, and a full extracranial neurovascular ultrasonography. Features evaluated were isolated increase of common carotid artery mean intima-media thickness (IMT) and extracranial atheromatous plaques.

Results: Intima-media thickness (IMT) was significantly higher in HCV-positive patients (1.04) than in HCV-negative patients (0.71). The percentage of plaque formation was insignificantly more frequent in HCV-positive patients (20\%) than HCV-negative patients (10\%). IMT and plaque formation were significantly increased in HCV-positive patients with high viremia. The multivariate analysis statistics concluded that infection with HCV was independently a risk factor for stroke.
\end{abstract}

Conclusion: Patients with HCV infection are at higher and earlier risk of stroke. The key mediator is inflammation. Lastly, researchers and clinicians should take these new findings into their consideration.

Keywords: HCV, Ischemic stroke, Carotid atherosclerosis

\footnotetext{
*Correspondence: Dr.reda_abdelrazek@yahoo.com

${ }^{1}$ Department of Neuropsychiatry, Suez Canal University, Ismailia, Egypt

${ }^{2}$ Department of Neurology, Faculty of Medicine, Suez Canal University, Ismailia, Egypt
} 


\section{Introduction}

Hepatitis $\mathrm{C}$ virus (HCV) infection is a worldwide endemic disease, with estimated prevalence of $3 \%$ all over the world, resulting in 170-200 million infected persons worldwide [1]. Egypt has been considered as the highest epidemic area of HCV infection all over the world, with an estimated prevalence of $14.7 \%$, resulting in $11,466,000$ infected persons with rate of 6/1000 new infections each year [2]. Chronic HCV infection may cause hepatic, metabolic, and extra hepatic diseases [3, 4]. Also, it has been claimed that atherosclerosis risk is much higher among those subjects with HCV markers [5, 6]. Destabilization of the carotid atheromatous plaque may have the main role in the risk of developing stroke. The plaque rupture and erosion lead to thrombus and embolus formation, with the consequences of brain ischemic injury. This process is responsible for about 20 to $30 \%$ of ischemic stroke patients. Inflammation seemed to be the crucial arbitrator for plaque rupture [7].Taking into consideration that $\mathrm{HCV}$ positive patients showed high levels of systemic inflammation [8], and the finding of human brain endothelial cells which act like receptors for $\mathrm{HCV}$ entry and replication make us to believe in a possible direct vascular damage in those patients [9].

\section{Aim}

The aim was to evaluate the relationship between the infection with HCV and the carotid atherosclerosis among patients with ischemic stroke.

\section{Patients}

This descriptive cross-sectional study was performed in the Neuropsychiatry Department, Suez Canal University Hospital, Ismailia, Egypt. Patients with established diagnosis of ischemic stroke were included and categorized into two groups. Group 1 consists of $50 \mathrm{HCV}$-positive patients, and group 2 consists of $50 \mathrm{HCV}$-negative patients. We excluded patients with cardiac source of emboli, non-vascular causes of neurological disorder, connective tissue disease, patients with malignancies, systemic infection in the preceding 8 weeks, and whom neuroimaging techniques demonstrated the presence of intracerebral hemorrhage. We also excluded patients who suffer from diabetes mellitus (DM) or dyslipidemia at $\mathrm{HCV}$-positive patients group in order to decrease the cofounders. Dyslipidemia is defined as (total blood cholesterol levels $>200 \mathrm{mg} / \mathrm{dl}$, low density lipoproteins levels $>130 \mathrm{mg} / \mathrm{dl}$, high density lipoproteins levels $<60 \mathrm{mg} / \mathrm{dl}$, or triglyceride levels $>150 \mathrm{mg} / \mathrm{dl}$ [10]. This study was approved by the Suez Canal Faculty of Medicine Ethical Committee, and all participants signed informed consent before inclusion in the study.

\section{Methods}

All subjects included were subjected to the following:
A. Clinical assessment including thorough history taking and full general and neurological examination using the National Institutes of Health Stroke Scale (NIHSS) [11, 12]. The Model for EndStage Liver Disease (MELD) score was used for assessing the severity of chronic liver disease [13]

B. Routine laboratory investigations including complete blood picture, erythrocyte sedimentation rate, C-reactive protein, fasting and postprandial blood glucose, liver function tests, renal function tests, and lipid profile. For all patients, HCV Ab seropositivity was assessed using ELISA assay, patients who were positive by ELISA were evaluated by PCR assay for serum HCV RNA positivity, and they subdivided into low and high viral load. Interpreting viral load test results, expressed as international units $(\mathrm{IU} / \mathrm{mL})$, low viral load is less than $800,000 \mathrm{IU} / \mathrm{mL}$ and high viral load is more than $800,000 \mathrm{IU} / \mathrm{mL}$ [14]

C. Electrocardiography and transesophageal echocardiography to detect cardiac source of emboli

D. CT scan and MRI of brain considered to support the clinical impression and to establish the diagnosis

E. Extra cranial carotid duplex study where carotid arteries was studied using a high resolution B-mode ultrasonography. The carotid arteries were studied by using a device (Philips HD11) with a linear probe $(7 \mathrm{MHz})$ which is available at the Radiology Department of Suez Canal University Hospital

\section{Position of the patient}

The patient was in a recumbent position with head slightly extended and turned $10^{\circ}$ to the opposite side. Using B-mode transverse scan of vessels to study the arterial wall morphology, we discovered intima-medial changes and existence of atheromatous plaques. Longitudinal section of the left and right common carotid artery, bulb, and the internal carotid artery (ICA) in each patient was scanned, and then evaluation of the intima-media thickness at the far wall of the common carotid artery (CCA) was done [15]. Estimation of the intima-media thickness was done with a computer-helped technique through the calculation of the difference between the first and the second interface (intima lumen and media adventitia) on the far wall of the common carotid artery in a plaque-free section which lies $10 \mathrm{~mm}$ below their bifurcations [16].

Each subject went through three measurements on both sides [17]. Maximum (outside the plaque) rather than mean values of IMT was considered. The average of IMT measurement on both sides was considered [18]. Carotid plaque was defined as the clearly identified focal 
Table 1 Clinical characteristics among the HCV-positive and HCV-negative patients

\begin{tabular}{llll}
\hline & $\begin{array}{l}\text { HCV-positive } \\
\text { patients }(n=50)\end{array}$ & $\begin{array}{l}\text { HCV-negative } \\
\text { patients }(n=50)\end{array}$ & $P$ value \\
\hline Smoking N (\%) & $26(52 \%)$ & $30(60 \%)$ & 0.5 \\
HTN N (\%) & $7(14 \%)$ & $15(30 \%)$ & $0.04^{*}$ \\
Previous stroke N (\%) & $0(0 \%)$ & $8(16 \%)$ & $0.02^{*}$ \\
\hline
\end{tabular}

*Statistically significant $P<0.05$

thickening of the intima-media layer in the wall of the common carotid arteries, internal carotid arteries, or the carotid bulb, measuring $1 \mathrm{~mm}$ or more [19].

\section{Statistical analysis}

We gathered data processed using SPSS version 22 (SPSS Inc., Chicago, IL, USA). Quantitative data were presented as means $\pm \mathrm{SD}$ while qualitative data were presented as numbers and percentages. Student $t$ test was used to compare between the two means while chi-squared test was used to compare between the qualitative data and logistic regression linear model to identify factors independently associated with ischemic cerebral stroke. Odds ratio was calculated for factors independently associated with ischemic cerebral stroke. $P$ value $<0.05$ was set as statistically significant, and $P$ value $<0.01$ was set as statistically highly significant.

\section{Results}

Age of patients ranged from 41 to 64 years with the mean of $50.73 \pm 7.1$. There were $58(58 \%)$ males and 42 (42\%) females. The mean age of patients with HCV-positive was $45 \pm 10$ years while it was $49 \pm 5$ years for HCV-negative patients. There were 27 males (54\%) and 23 females (46\%) patients in HCV-positive patients, versus 31 males (62\%) and 19 females (38\%) patients in HCV-negative patients. There was no statistically significant difference between both groups regarding age and sex $(P$ value $=0.1$ and 0.4 respectively $)$.

Vascular risk factors among both groups showed a higher preponderance among HCV-negative patients than $\mathrm{HCV}$ positive patients. On the other hand, there was no statistically significant difference between the two groups regarding smoking status and NIHSS score (Tables 1 and 2).

Regarding the extra-cranial duplex findings among HCV-positive patients and HCV-negative patients, the

Table 2 NIHSS score among the HCV-positive and HCVnegative patients

\begin{tabular}{llll}
\hline NIHSS & $\begin{array}{l}\text { HCV-positive } \\
\text { patients }(n=50)\end{array}$ & $\begin{array}{l}\text { HCV-negative } \\
\text { patients }(n=50)\end{array}$ & $P$ value \\
\hline$<5$ & $3(6 \%)$ & $2(4 \%)$ & 0.8 \\
$5-15$ & $39(78 \%)$ & $43(86 \%)$ & 0.5 \\
$>15$ & $8(16 \%)$ & $5(10 \%)$ & 0.6 \\
\hline
\end{tabular}

NIHSS National Institutes of Health Stroke Scale
Table 3 Carotid intima-media thickness difference among HCVpositive and HCV-negative patients

\begin{tabular}{|c|c|c|c|}
\hline & $\begin{array}{l}\text { HCV-positive } \\
\text { patients }(n=50)\end{array}$ & $\begin{array}{l}\text { HCV-negative } \\
\text { patients }(n=50)\end{array}$ & $P$ value \\
\hline $\begin{array}{l}\text { IMT (in mm) } \\
(\text { mean } \pm S D)\end{array}$ & $1.04 \pm 0.23$ & $0.71 \pm 0.13$ & $<0.001^{* *}$ \\
\hline
\end{tabular}

carotid intima-media thickness (IMT) was statistically significantly higher among those patients with $\mathrm{HCV}$-positive than those with HCV-negative (Tables 3 and 4). Also, plaque formation in $\mathrm{HCV}$-positive patients was more frequent than in $\mathrm{HCV}$-negative patients (10\%). However, the difference is statistically non-significant (Table 5).

Plaques were significantly more frequent at the CCA and ICA in HCV-positive patients and at the carotid bulb in $\mathrm{HCV}$-negative patients $(P$ value $<0.001)$. There was no significant difference detected between $\mathrm{HCV}$-positive patients and HCV-negative patients regarding plaque homogeneity, echogenicity, or surface $(P$ value $>0.05)$ (Table 6$)$.

Regarding the relation between the severity of the hepatitis $\mathrm{C}$ virus infection and the severity of the atherosclerosis among patients with HCV-positive, there was a difference between patients with low and high viremia as those with high viremia had more significant increase in IMT and also in plaque formation. There was no significant relation between MELD score and severity of atherosclerosis (Tables 7 and 8).

Multiple logistic regression analysis including other confounding risk factors, male sex, smoking, hypertension, dyslipidaemia, diabetes mellitus, and hepatitis $\mathrm{C}$ virus of atherosclerosis, revealed that HCV infection was positively and independently associated with isolated elevation of CCA mean IMT with an OR of 2.07 (95\% CI $1.50-2.85)$ and $(P$ value $<0.0001)$ (Table 9$)$.

Multiple logistic regression analysis including other confounding risk factors, male sex, smoking, dyslipidaemia, hypertension, diabetes mellitus, and hepatitis $\mathrm{C}$ virus of atherosclerosis, revealed that $\mathrm{HCV}$ infection was positively and independently associated with presence of carotid plaques with an OR of 5.61 (95\% CI 2.06-15.26) and $(P$ value $<0.001)$ (Table 10$)$.

Table 4 Intima-media thickness difference among HCV-positive and HCV-negative patients

\begin{tabular}{llll}
\hline & $\begin{array}{l}\text { HCV-positive } \\
\text { patients N (\%) }\end{array}$ & $\begin{array}{l}\text { HCV-negative } \\
\text { patients N (\%) }\end{array}$ & P value \\
\hline IMT $<1 \mathrm{~mm}$ & $10(20 \%)$ & $34(68 \%)$ & $<0.001^{* *}$ \\
IMT $>1 \mathrm{~mm}$ & $40(80 \%)$ & $16(32 \%)$ & $<0.001^{* *}$ \\
\hline
\end{tabular}

IMT intima-media thickness, $\mathrm{mm}$ millimete

**Statistically highly significant $P<0.001$ 
Table 5 Plaque formation among HCV-positive and HCVnegative patients

\begin{tabular}{lccc}
\hline & $\begin{array}{l}\text { HCV-positive } \\
\text { patients }(n=50)\end{array}$ & $\begin{array}{l}\text { HCV-negative } \\
\text { patients }(n=50)\end{array}$ & $P$ value \\
\hline Plaques N (\%) & $10(20 \%)$ & $5(10 \%)$ & 0.1 \\
\hline
\end{tabular}

\section{Discussion}

The purpose of this study was to detect the relationship between HCV infection and carotid atherosclerosis in patients with ischemic stroke. This was achieved by determining whether $\mathrm{HCV}$ infection constitutes a significant difference in the risk of developing carotid atherosclerosis or not and by detecting the proportion and pattern of carotid atherosclerosis in HCV-infected patients. In this study, the main focus was the data analysis for measurable findings in the cardiovascular system. So, HCV infection among stroke patients was independently studied regardless the effect of the other risk factors and confounders of stroke. We also excluded patients who suffer from DM or dyslipidemia in the HCV-positive patients group in order to decrease the confounders.

Many studies found a positive link between HCV infection and the important risk factors for stroke including the type 2 diabetes mellitus among other metabolic syndromes [20-23]. This study excluded diabetes to make sure to evaluate the effect of $\mathrm{HCV}$ infection in stroke furthermore independently.

In this study, carotid intima-media thickness showed higher statistically significant difference among those $\mathrm{HCV}$-positive patients than those with $\mathrm{HCV}$-negative $(P$ value $<0.001)$. IMT $>1 \mathrm{~mm}$ was statistically significantly more frequent among $\mathrm{HCV}$-positive patients (80\%) than

Table 6 Plaque morphology among HCV-positive and HCVnegative patients

\begin{tabular}{|c|c|c|c|}
\hline $\begin{array}{l}\text { Plaque } \\
\text { morphology }\end{array}$ & $\begin{array}{l}\text { HCV-positive } \\
\text { patients }\end{array}$ & $\begin{array}{l}\text { HCV-negative } \\
\text { patients }\end{array}$ & $P$ value \\
\hline \multicolumn{4}{|l|}{ Location } \\
\hline Common carotid & $6(60 \%)$ & $1(20 \%)$ & $<0.04^{*}$ \\
\hline Carotid bulb & $1(10 \%)$ & $4(80 \%)$ & $<0.03^{*}$ \\
\hline Internal carotid & $3(30 \%)$ & 0 & $<0.05^{*}$ \\
\hline \multicolumn{4}{|l|}{ Homogeneity } \\
\hline Homogenous & $7(70 \%)$ & $3(60 \%)$ & 0.5 \\
\hline Heterogeneous & $3(30 \%)$ & $2(40 \%)$ & \\
\hline \multicolumn{4}{|l|}{ Echogenicity } \\
\hline Echogenic & $6(60 \%)$ & $4(80 \%)$ & 0.09 \\
\hline Echolucent & $4(40 \%)$ & $1(20 \%)$ & \\
\hline \multicolumn{4}{|l|}{ Surface } \\
\hline Regular & $6(60 \%)$ & $3(60 \%)$ & 0.07 \\
\hline Irregular & $3(30 \%)$ & $2(40 \%)$ & \\
\hline Ulcerated & $1(1 \%)$ & 0 & \\
\hline
\end{tabular}

*Statistically significant $P<0.05$
Table 7 Relation between MELD score, viral load, and IMT among HCV-positive patients

\begin{tabular}{llll}
\hline & \multicolumn{1}{l}{ IMT } & $>1$ & $P$ value \\
\cline { 2 - 3 } & $<1$ & & \\
\hline MELD score & & 23 & 0.6 \\
0 to $<9$ & 31 & 7 & \\
$9-12$ & 17 & 9 & $<0.05^{*}$ \\
$>12$ & 13 & & \\
Viral load & & $5(8.2 \%)$ & \\
Low & $9(23.1 \%)$ & $28(71.8 \%)$ & \\
High & $8(13.1 \%)$ & & \\
\hline
\end{tabular}

MELD The Model for End-Stage Liver Disease, IMT intima-media thickness *Statistically significant $P<0.05$

among HCV-negative patients $(32 \%)$ ( $P$ value $<0.001)$, which agreed with Boddi and his colleagues who found that IMT > $1 \mathrm{~mm}$ was highly statistically more prevalent among anti-HCV-positive subjects than among controls [24]. Meanwhile, Targher and his colleagues stated that HCV infection was an independent predictor of the increased carotid IMT [25].

Regarding the frequency and the intensity of infection, a 2.5-year follow-up study on several serological markers of infectious agents showed that individuals who had been exposed to an increased number of infectious pathogens had an elevated risk of atherosclerosis [26].

In the current study, we found that HCV-positive patients with high viral load were more prone to the increase in carotid IMT (71.8\%) than those with low viral load (5\%). This finding is supported by Adinolfi and his colleagues who found that $\mathrm{HCV}$ infection is a risk factor for early formation of carotid atherosclerosis through the viral load and steatosis with the modulation of the atherogenic factors such as inflammation [6]. Lee and his colleagues also, in a community-based prospective cohort study, concluded that chronic HCV infection is an independent risk predictor of cerebrovascular deaths, showing a severity-dependent cerebrovascular mortality with increasing serum HCV RNA level [27].

Table 8 Relation between MELD score, viral load, and plaque formation among HCV-positive patients

\begin{tabular}{lcc}
\hline & Plaque & $P$ value \\
\hline MELD score & & \\
0 to $<9$ & 4 & 0.5 \\
$9-12$ & 4 & \\
$>12$ & 2 & $<0.05^{*}$ \\
Viral load & & \\
Low & 3 & \\
High & 7 & \\
\hline
\end{tabular}

MELD The Model for End-Stage Liver Disease *Statistically significant $P<0.05$ 
Table 9 Predictors for intima-media thickness

\begin{tabular}{lll}
\hline & Odds ratio $(95 \% \mathrm{Cl})$ & $P$ value \\
\hline Sex (male) & $1.01(0.72-1.42)$ & 0.95 \\
Smoking & $1.20(1.03-1.41)$ & $<0.05^{*}$ \\
Dyslipidaemia & $1.02(0.92-1.13)$ & 0.72 \\
hypertension & $1.02(0.79-1.33)$ & 0.85 \\
Diabetes mellitus & $1.01(0.87-1.17)$ & 0.91 \\
Hepatitis C virus & $2.07(1.50-2.85)$ & $<0.0001^{* *}$
\end{tabular}

Odds ratio derived from logistic regression analysis including all the variables $\mathrm{Cl}$ confidence interval

* Statistically significant $P<0.05$

** Statistically highly significant $P<0.001$

Regarding carotid plaque formation, we found that the percentage of plaque formation in $\mathrm{HCV}$-positive patients was more frequent (20\%) than in HCV-negative patients (10\%). However, the difference is statically non-significant $(P$ value $>0.05$ ). Ishizaka and his colleagues found that individuals seropositive for $\mathrm{HCV}$ core protein had 5.6 times risk of developing carotid plaque [28]. Aslam and his colleagues also, in their research review, concluded the higher incidence of carotid atherosclerotic plaques among $\mathrm{HCV}$-positive patients than HCV-negative individuals [29].

Regarding presence of a relation between stroke severity and atherosclerosis, statically significant difference have been found between the two groups of patients (HCV-positive and HCV-negative), according to the IMT, in those patients whose NIHSS stroke scale ranged from 5 to 15 only.

In contrast, regarding relation between $\mathrm{HCV}$ severity and atherosclerosis in $\mathrm{HCV}$-positive patients, there was a difference between patients with low and high viremia as those with high viremia had more significant increase in IMT and also in plaque formation as we discussed before, while there was no significant relation between MELD score and severity of atherosclerosis.

The data of this study showed that HCV infection is a risk factor associated with stroke after controlling for the major traditional risk factors (O.R 2.07, 95\% C.I. $1.50-2.85, P<0.0001)$. The results of our study mirror those recently published by Adinolfi and his colleagues

Table 10 Predictors for carotid plaques

\begin{tabular}{lll}
\hline & Odds ratio $(95 \% \mathrm{Cl})$ & $P$ value \\
\hline Sex (male) & $2.76(2.41-3.15)$ & $0.01^{*}$ \\
Smoking & $1.06(0.92-1.22)$ & 0.08 \\
Dyslipidaemia & $1.01(0.30-1.36)$ & 0.13 \\
hypertension & $1.37(0.86-2.18)$ & 0.17 \\
Diabetes mellitus & $1.24(0.92-1.68)$ & 0.15 \\
Hepatitis C virus & $5.61(2.06-15.26)$ & $<0.001^{* *}$
\end{tabular}

Odds ratio derived from logistic regression analysis including all the variables Cl confidence interval

* Statistically significant $P<0.05$

**Statistically highly significant $P<0.001$ who demonstrated, in a retrospective case control study, that $\mathrm{HCV}$ infection is associated with an increased risk of ischemic stroke [30]. And, similar to that published by Liao and his colleagues, who demonstrated, in a large prospective population-based cohort, that the cumulative risk of stroke for $\mathrm{HCV}$ positive subjects was significantly higher than those without HCV infection [31].

\section{Conclusion}

This study concluded that patients with HCV infection are at higher and earlier risk of stroke. The key mediator is inflammation. Lastly, researchers and clinicians should take these new findings into their consideration.

\section{Abbreviations}

CCA: Common carotid artery; DM: Diabetes mellitus; ELISA: Enzyme-linked immunosorbent assay; HCV: Hepatitis C virus; HCV Ab: Hepatitis C virus antibody; HCV RNA: Hepatitis C virus ribonucleic acid; ICA: Internal carotid artery; IMT: Intima-media thickness; MELD score: Model for End-Stage Liver Disease; NIHSS: National Institutes of Health Stroke Scale; PCR: Polymerase chain reaction; U/S: Ultrasonography

\section{Acknowledgements}

"Not applicable".

\section{Funding}

The Authors were responsible for the cost of this study including the design of the study and collection, analysis, and interpretation of data and in writing the manuscript and no funding.

\section{Availability of data and materials}

Availability of data and materials: the data can be publicly available at the Faculty of Medicine, Suez Canal University.

\section{Authors' contributions}

OA carried out the study conception and design, participated in its design and coordination, and drafted the manuscript. AY carried out the design of the study, carried out the analysis and interpretation of data, and helped to draft the manuscript. AR participated in the sequence alignment, interpretation of data, and drafting of the manuscript. MD participated in the acquisition of data and performed the statistical analysis. All authors read and approved the final manuscript.

Ethics approval and consent to participate

The study was approved by the Ethics committee of Suez Canal Faculty of medicine in April 29, 2015. Committee Number: 2413 An informed consent was taken from all the participants in the study.

Consent for publication

Participants signed an informed consent for publication.

\section{Competing interests}

The authors declare that they have no competing interests (financial or nonfinancial).

\section{Publisher's Note}

Springer Nature remains neutral with regard to jurisdictional claims in published maps and institutional affiliations.

Received: 3 December 2017 Accepted: 4 January 2019

Published online: 16 January 2019

\section{References}

1. SD ANNEMARIEWASLEY, Alter MJ. Epidemiology of hepatitis C: geographic differences and temporal trends. Hepat C State Art Millenn Thieme. 2000; 20(1):1. 
2. El-Zanaty F, Way AA. Egypt demographic and health survey 2000. Cairo Egypt Ministry of Health and Population 2001 Jan; 2006.

3. Lonardo A, Adinolfi LE, Loria P, Carulli N, Ruggiero G, Day CP. Steatosis and hepatitis $C$ virus: mechanisms and significance for hepatic and extrahepatic disease. Gastroenterology. Elsevier. 2004;126(2):586-97.

4. Khattab MA, Eslam M, Alavian SM. Hepatitis C virus as a multifaceted disease: a simple and updated approach for extrahepatic manifestations of hepatitis $C$ virus infection. Hepat Mon Kowsar Medical Institute. 2010;10(4):258.

5. Boddi M, Abbate R, Chellini B, Giusti B, Giannini C, Pratesi G, et al. Hepatitis C virus RNA localization in human carotid plaques. J Clin Virol Elsevier. 2010; 47(1):72-5.

6. Adinolfi LE, Restivo L, Zampino R, Guerrera B, Lonardo A, Ruggiero L, et al. Chronic HCV infection is a risk of atherosclerosis. Role of HCV and HCVrelated steatosis. Atherosclerosis. 2012;221(2):496-502 [cited 2015 Nov 21].

7. Stoll G, Bendszus M. Inflammation and atherosclerosis novel insights into plaque formation and destabilization. Stroke Am Heart Assoc. 2006;37(7): 1923-32.

8. Lonardo A, Lombardini S, Scaglioni F, Carulli L, Ricchi M, Ganazzi D, et al. Hepatic steatosis and insulin resistance: does etiology make a difference? J Hepatol Elsevier. 2006:44(1):190-6.

9. Fletcher NF, Wilson GK, Murray J, Hu K, Lewis A, Reynolds GM, et al. Hepatitis $C$ virus infects the endothelial cells of the blood-brain barrier. Gastroenterology Elsevier. 2012;142(3):634-43.

10. Catapano A, Graham I, De Backer G, Wiklund O, Chapman M, Drexel H, Hoes A, Jennings C, Landmesser U, Pedersen T, Reiner Ž, Riccardi G, Taskinen M, Tokgozoglu L, Verschuren W, Vlachopoulos C, Wood D, Zamorano J. 2016 ESC/EAS Guidelines for the Management of Dyslipidaemias. Eur Heart J. 2016;37(39):2999-3058. https://doi.org/10.1093/eurheartj/ehw272. Epub 2016 Aug 27.

11. NIH Stroke Scale Training,Part 2. Basic instruction. Department of Health and Human Services, National Institute of Neurological Disorders and Stroke. The National Institute of Neurological Disorders and Stroke (NINDS) Version 2.0. https://catalog.ninds.nih.gov/ninds/product/NIH-Stroke-Scale-Training-DVDversion-2-0-/NDS-511.

12. Hage $\mathrm{V}$. The NIH stroke scale: a window into neurological status. Nursing Spectrum. 2011;24(15):44-9.

13. Kamath PS, Wiesner RH, Malinchoc M, Kremers W, Therneau TM, Kosberg CL, D'Amico G, Dickson ER, Kim WR. A model to predict survival in patients with end-stage liver disease. Hepatology. 2001;33(2):464-70.

14. Hepatitiscnewdrugs.blogspot.com.eg. Available at: https:// hepatitiscnewdrugs.blogspot.com/2011/03/hepatitis-c-viral-load-test.html. Accessed 3 Mar 2011.

15. Bathala L, Mehndiratta MM, Sharma VK. Cerebrovascular ultrasonography: technique and common pitfalls. Annals of Indian Academy of Neurology. 2013;16(1):121-7.

16. Casella IB, Presti C, Porta RMP, Sabbag CRD, Bosch MA, Yamazaki Y. A practical protocol to measure common carotid artery intima-media thickness. clinics sao paulo B razil. 2008;63(4):515-20 14

17. Wikstrand J. Methodological considerations of ultrasound measurement of carotid artery intima-media thickness and lumen diameter. Clinical Physiology and Functional Imaging. 2007;27(6):341-5.

18. Luo $X$, Yang Y, Cao T, Li Z. Differences in left and right carotid intima-media thickness and the associated risk factors. Clin Radiol. 2011;66(5):393-8.

19. Ishizaka N, Ishizaka Y, Takahashi E, Tooda E, Hashimoto H, Nagai R, Yamakado M. Association between hepatitis C virus seropositivity, carotidartery plaque, and intima-media thickening. Lancet. 2002;359(9301):133-5.

20. Biffi A, Devan WJ, Anderson CD, Cortellini L, Furie KL, Rosand J, et al. Statin treatment and functional outcome after ischemic stroke case-control and meta-analysis. Stroke Am Heart Assoc. 2011;42(5):1314-9.

21. Shah NR, Ogedegbe G, ACP Journal Club. Review: first-line low-dose thiazides and ACE inhibitors reduce mortality and morbidity in adults with hypertension. Ann Intern Med. 2010;152(2):JC1.

22. Rouabhia S, Malek R, Bounecer H, Dekaken A, Bendali Amor F, Sadelaoud M, et al. Prevalence of type 2 diabetes in Algerian patients with hepatitis $C$ virus infection. World J Gastroenterol. 2010;16(27):3427-31.

23. Sheikh MY, Choi J, Qadri I, Friedman JE, Sanyal AJ. Hepatitis C virus infection: molecular pathways to metabolic syndrome. Hepatology Wiley Online Library. 2008;47(6):2127-33.

24. Boddi M, Abbate R, Chellini B, Giusti B, Solazzo V, Sofi F, et al. HCV infection facilitates asymptomatic carotid atherosclerosis: preliminary report of HCV
RNA localization in human carotid plaques. Dig Liver Dis. 2007[cited 2016 Jan 16];39:S55-60.

25. Targher G, Bertolini L, Padovani R, Rodella S, Arcaro G, Day C. Differences and similarities in early atherosclerosis between patients with non-alcoholic steatohepatitis and chronic hepatitis B and C. J Hepatol. 2007;46(6):1126-32 [cited 2016 Jan 16].

26. Espinola-Klein C, Rupprecht H-J, Blankenberg S, Bickel C, Kopp H, Victor A, et al. Impact of infectious burden on progression of carotid atherosclerosis. Stroke. 2002;33(11).

27. Lee $M-H$, Yang $H-I$, Wang $C-H$, Jen C-L, Yeh S-H, Liu C-J, et al. Hepatitis C virus infection and increased risk of cerebrovascular disease. Stroke Am Heart Assoc. 2010;41(12):2894-900.

28. Ishizaka Y, Ishizaka N, Takahashi E, Unuma T, Tooda E, Hashimoto H, et al. Association between hepatitis $C$ virus core protein and carotid atherosclerosis. Circ J [Internet]. 2003:67(1):26-30

29. Aslam F, Alam M, Lakkis NM. Hepatitis $C$ and carotid atherosclerosis: a retrospective analysis. Atherosclerosis. 2010;209(2):340-3 [cited 2014 Sep 27].

30. Adinolfi LE, Restivo L, Guerrera B, Sellitto A, Ciervo A, luliano N, et al. Chronic HCV infection is a risk factor of ischemic stroke. Atherosclerosis. Elsevier. 2013[cited 2016 Jan 12];231(1):22-6.

31. Liao C-C, Su T-C, Sung F-C, Chou W-H, Chen T-L. Does hepatitis C virus infection increase risk for stroke? A population-based cohort study. PLoS One. 2012[cited 2014 Sep 27];7(2):e31527.

\section{Submit your manuscript to a SpringerOpen ${ }^{\circ}$ journal and benefit from:}

- Convenient online submission

- Rigorous peer review

- Open access: articles freely available online

- High visibility within the field

- Retaining the copyright to your article

Submit your next manuscript at $\boldsymbol{\nabla}$ springeropen.com 